\title{
Aining Granule Stabilizes the Decline of CD4 Cell Count in HAART-Receiving HIV/AIDS Patients Having Virologic Failure
}

Leung Ka-kit Ross ${ }^{1^{*}}$, Li Fong Sue Frances ${ }^{1}$, Cen Yu-wen ${ }^{2}, \mathrm{Xu} \mathrm{Yang}^{3}$ and Wang Jian ${ }^{4}$

${ }^{1}$ Stanley Ho Centre for Emerging Infectious Diseases, the Chinese University of Hong Kong SAR, China

${ }^{2}$ Department of Infectious Diseases, Guangzhou 8th People's Hospital, Guangzhou (510060), China

${ }^{3}$ Division of Genomics and Bioinformatics, CUHK-BGI Innovation Institute of Trans-omics, China

${ }^{4}$ Traditional Chinese Medicine Center for AIDS Prevention and Treatment, China Academy of Chinese Medicine Sciences, Beijing (100700), China

\begin{abstract}
Objective: To explore the pattern of slow-down of CD4 T cell depletion by Aining granule administration.

Method: The data of prospective, randomized, placebo-controlled and double blinded clinical trials enrolling one hundred HIVIAIDS individuals, randomized into two groups, one with 50 cases administered with Aining granule plus the combination of d4T, ddl and NVP, and the other received with placebo plus the combination of d4T, ddl and NVP for observing in a duration of 11 months in were re-analyzed to observe the course of different CD T cells over the treatment period.
\end{abstract}

Results: Only the patients in the Aining granule treatment group (7, vs 0 in the control group, deviation exceeding 2 sigmas) had stable CD4 T cell count over the treatment course.

Conclusion: Our results provided insights into molecular investigation of the relation between the active ingredients of Aining granule, DNA replication and HIV-induced CD4 T cell death.

Keywords: Aining granule; Cluster of differentiation; Highly-active antiretroviral therapy; Human immunodeficiency virus; Acquired immunodeficiency syndrome

\section{Introduction}

China and some developing countries still have vast regions that older regimen of Highly Active Antiretroviral Therapy (HAART) is being administered [1]. Moreover, the side-effects of HAART usually result in poor compliance [2]. According to UNAIDS 2012 China AIDS Response Progress Report, China has a population of 780,000 people living with HIV/AIDS (PLHIV). While HAART is the mainstream medicine in many countries, in China Chinese medicine has also been widely used as auxiliary medicine to ameliorate the side-effects of HAART [3-6]. Chinese medicine herbal formulas were found to be effective in promoting T lymphocytes either in the early or intermediate stages of HIV infection [7] or advanced AIDS [8], though the mechanisms remain to be elucidated. Due to social belief, HAART availability and toxicity considerations, Chinese medicine is also used solely by a significant number of PLHIV in China [9]. Previously we reported that combination therapy of HAART and Aining granule had resulted in a slower depletion of CD4 T cells and improvement in signs and symptoms, without any apparent adverse effects [10]. In spite of statistically significant results, we only compared time point to time point but did not take the course into consideration. Moreover, it is not known how the slowdown in $\mathrm{CD} 4 \mathrm{~T}$ cell decline is related to the course. Bioinformatics techniques were used to explore patterns in various settings [11-15] and an in-depth pattern discovery shall shed light for better design of molecular experiments, drug administration and policy making.

\section{Method}

Patients met the inclusion criteria if they were absent of any other disease than HIV / AIDS. Otherwise they were excluded. A total of 100 patients with informed consent from Queshan County, Henan Province contracting HIV via compensated plasma donation infection had been recruited to a double blinded controlled study to compare the effect of HAART with and without Aiming granule administration.
The patients were randomly assigned into the treatment group or the control group by central random voice systems at the clinical evaluation center of the Chinese Academy of Traditional Chinese Medicine. Patient demographics i.e. age and gender of the patients were averaged and recorded.

During an 11-month study period, the Aining treatment group was given Aining granule and HAART (in combination of d4T, ddI and NVP); the control group was given the HAART only. Both of the groups were inspected monthly by conducting routine blood, urine and stool tests at the clinical laboratory of Henan Province Queshan Hospital. CD4, CD8, CD3 and CD45RA cell counts at baseline and the $3^{\text {rd }}, 6^{\text {th }}$ and $11^{\text {th }}$ month during the study period had been investigated.

Vacutainer blood collection tubes containing EDTA were used to collect blood samples. Peripheral blood mononucleated cells were prepared using conventional method and stored in liquid nitrogen before use. The stored samples were transferred to a $37^{\circ} \mathrm{C}$ waterbath for resuscitation. Phosphate buffered saline was used to rinse the cells twice before adding fluorescent labeled monoclonal antibodies for CD3, CD8, CD45 and CD4. The mixture was shaken and incubated at room temperature in the dark for 20 minutes, followed by addition of hemolysin. The samples were then shaken and incubated in the dark at room temperature for another 8 minutes. BD FACSC Calibur and

${ }^{*}$ Corresponding author: Leung Ka-Kit Ross, Stanley Ho Centre for Emerging Infectious Diseases, the Chinese University of Hong Kong SAR, China, Tel: (852) 2252 8812; E-mail: ross@cuhk.edu.hk

Received November 28, 2014; Accepted January 31, 2015; Published February 07, 2015

Citation: Ross LK, Frances LFS, Yu-wen C, Yang X, Jian W (2015) Aining Granule Stabilizes the Decline of CD4 Cell Count in HAART-Receiving HIVIAIDS Patients Having Virologic Failure. J Data Mining Genomics Proteomics 6: 165. doi:10.4172/2153-0602.1000165

Copyright: (c) 2015 Ross LK, et al. This is an open-access article distributed unde the terms of the Creative Commons Attribution License, which permits unrestricted use, distribution, and reproduction in any medium, provided the original author and source are credited. 
FITC-IgGl/PE-IgGl/PFcy5-IgG1 were used for cell sorting. For each sample at least 10,000 cells were used for detection. Aining granules had been procured from Shanghai Sunshine Biotechnology Ltd. (batch number: 2005L01872). Patients with records of poor compliance and missing any records at $0,3,6$ and 11 months during the study period were excluded for further analysis.

Statistical analysis by either Wilcoxon rank sum test with continuity correction or Fisher's exact test, wherever appropriated, was performed. Self-organizing map was generated by R (version 2.15.2) to demonstrate the change of various $\mathrm{CD} \mathrm{T}$ cells count over the study period. Eight clusters were used to classify the patterns in the course of $\mathrm{CD} 4, \mathrm{CD} 3, \mathrm{CD} 8$ and CD45RA T cells to represent increase or decrease for the transition between $0,3,6$ and 11 months after the initiation of HAART (and Aining treatment in the treatment group).

\section{Results}

The data of previously recruited 100 HIV/AIDS patients were retrieved. Six of them manifested very poor compliance and were excluded from subsequent analysis. Only 33 patients in Aining granule treatment and 24 patients in control groups contained complete information in the CD4, CD3, CD8 and CD45RA T cell course. The details of demographical and clinical information are summarized in Table 1.

All the attributes were not significantly associated. The decline in CD4 $\mathrm{T}$ cell counts at baseline and 11 months post-HAART with $(-72.5)$ and without Aining granule administration $(-119)$ was significant (U-test, 0.044), a result comparable to our previously reported values [10]. Figure 1A shows the course of CD4, CD3, CD8 and CD45RA $\mathrm{T}$ cells. There were no apparent differences in the course of specific CD T cell change for the two groups, except that CD4 T cell count remained stable for 7 HIV/AIDS patients in the Aining granule treatment group (Figure 1A, CD4, prototype F). Since there were 33 and 24 patients in the Aining granule treatment and control groups, respectively, an assumption of random distribution of the two groups over the CD $\mathrm{T}$ cell count will yield an average difference of $33 / 24=1.375$. In other words, $0-2$ more patients having received Aining treatment is expected. In fact, Figure $1 \mathrm{~B}$ supports this idea and a normal distribution was observed. Double peaks are expected because all the differences were integer. The extreme value of 7 (deviation exceeding 2 sigmas) again suggests that CD4 T cell count remaining stable might be the major effect of Aining granule. The courses of CD3 and CD8 T cells were similar (Figure 1A) and these were also supported by high Spearman's rank correlation coefficients (Table 2).

\section{Discussion}

Virologic failure is particularly problematic in rural areas due to poor compliance [16]. Although the emergence of HIV drug resistance (HIVDR) also poses a threat to the long-term success and durability of HAART [17], a significant proportion of patients in virologic failure had no drug resistance identified in a large cross-sectional cohort study in China, suggesting that treatment adherence could contribute significantly to the success of treatment [18].

Our results showed that over the 11-month treatment period, only the CD4 $\mathrm{T}$ cell count had a significant difference between Aining administration and control group. The decline was also not retarded immediately, but after a period of 11 months, in concordance with our previously published result [10]. Here we provided additional evidence that the slowdown was partly contributed by a group of patients that managed to maintain CD4 T cell count. Collectively, Aining granule might play a role in stabilizing CD4 T cell count in some patients while slightly slowing down the decline of CD4 T cell count in others over an extended period. By dissecting the course of different CD T cells over the treatment period, we also showed that there was no difference between the two groups in CD T cells other than CD4, implying CD4 $\mathrm{T}$ cell regeneration (reflected by CD45RA cell count) was not affected. CD8 cells were also found not significantly influenced by the Aining granule. During the course of AIDS progression, CD4 T cell counts
A)
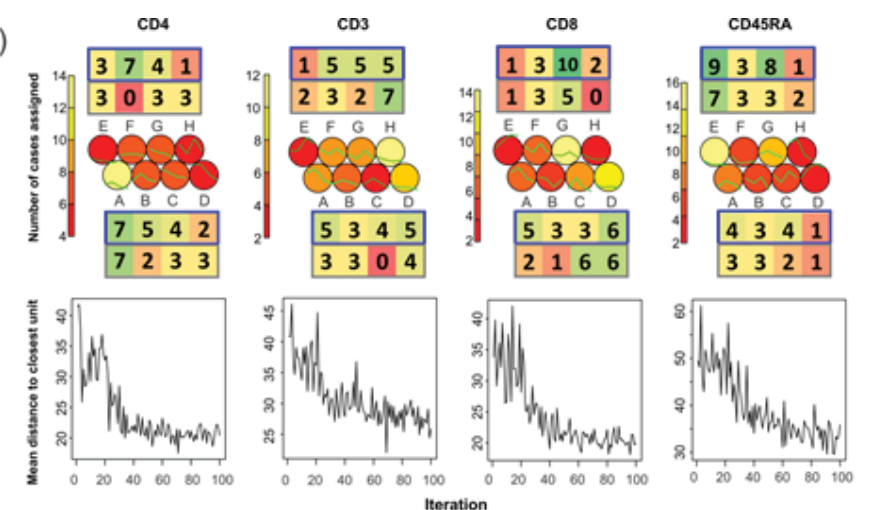

B)

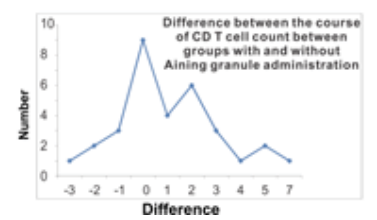

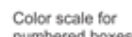

012345678910

Figure 1: Change of CD4, CD3, CD8 and CD45RA T cell count over an 11-month period during receiving HAART with and without Aining granule administration. A) Upper panel: Prototypic CD T cell course and the number of cases assigned. The prototypes are named A to $H$ in specific CD T cell count to facilitate discussion. The numbers in colored boxes above and below each prototype represent the number of cases belonged to a particular prototype for the cases with (above) and without (below) Aining granule administration. Lower panel: Convergence was attained at about the $60^{\text {th }}$ iteration for most cases. B) The difference between the course of CD T cell count between groups with and without Aining granule administration. 
Citation: Ross LK, Frances LFS, Yu-wen C, Yang X, Jian W (2015) Aining Granule Stabilizes the Decline of CD4 Cell Count in HAART-Receiving HIVI AIDS Patients Having Virologic Failure. J Data Mining Genomics Proteomics 6: 165. doi:10.4172/2153-0602.1000165

Page 3 of 4

\begin{tabular}{|c|c|c|c|}
\hline & \multicolumn{2}{|c|}{ Frequency/Median } & \multirow[b]{2}{*}{ p-value $\#$} \\
\hline Category & with Aining & without Aining & \\
\hline \multicolumn{4}{|l|}{ Gender } \\
\hline Male & 13 & 5 & \multirow{2}{*}{0.161} \\
\hline Female & 20 & 19 & \\
\hline Age & 43 & 39 & 0.082 \\
\hline \multicolumn{4}{|c|}{ CD4 count (months after treatment) } \\
\hline baseline & 278 & 339.5 & 0.485 \\
\hline 3 months after HAART & 317 & 321.5 & 0.841 \\
\hline 6 months after HAART & 254 & 286 & 0.626 \\
\hline 11 months after HAART & 227 & 218 & 0.968 \\
\hline Annual difference & -72.5 & -119 & 0.044 \\
\hline \multicolumn{4}{|l|}{ CD8 count } \\
\hline baseline & 880 & 735.5 & 0.626 \\
\hline 3 months after HAART & 848 & 586.5 & 0.258 \\
\hline 6 months after HAART & 847 & 686 & 0.516 \\
\hline 11 months after HAART & 675 & 625 & 0.536 \\
\hline Annual difference & -154 & -135 & 0.828 \\
\hline \multicolumn{4}{|l|}{ CD3 count } \\
\hline baseline & 1130 & 1162.5 & 0.865 \\
\hline 3 months after HAART & 1113 & 923.5 & 0.604 \\
\hline 6 months after HAART & 1217 & 1122 & 0.893 \\
\hline 11 months after HAART & 934 & 913.5 & 0.879 \\
\hline Annual difference & -197 & -272 & 0.390 \\
\hline \multicolumn{4}{|c|}{ CD45RA count } \\
\hline baseline & 1552 & 1504.5 & 0.892 \\
\hline 3 months after HAART & 1603 & 1169 & 0.465 \\
\hline 6 months after HAART & 1442 & 1616.5 & 0.66 \\
\hline 11 months after HAART & 1228 & 1220 & 0.765 \\
\hline Annual difference & -303 & -361 & 0.456 \\
\hline \#Wilcoxon rank sum & $\begin{array}{l}\text { vith contin } \\
\text { rmed whe }\end{array}$ & $\begin{array}{l}\text { rrection anc } \\
\text { ropriate }\end{array}$ & st were \\
\hline
\end{tabular}

Table 1: Summary of patient characteristics

\begin{tabular}{|c|c|c|}
\hline Time point & $\begin{array}{l}\text { Spearman's rank } \\
\text { correlation rho }\end{array}$ & $\mathrm{k}$-value \\
\hline baseline & 0.921 & $<0.001$ \\
\hline 3 months after HAART & 0.911 & $<0.001$ \\
\hline 6 months after HAART & 0.950 & $<0.001$ \\
\hline 11 months after HAART & 0.918 & $<0.001$ \\
\hline
\end{tabular}

Table 2: The correlation between CD3 and CD8 T cell count during the course of treatment decreased while the other CD T cell counts were less affected, it is expected that the ratio of CD4:CD8 should also follow the decreasing trend. Since the biomarker CD3 actually mainly represents $\mathrm{CD} 3+\mathrm{CD} 4+$ and $\mathrm{CD} 3+\mathrm{CD} 8+\mathrm{T}$ cells, a strong correlation between the course of $\mathrm{CD} 3$ and $\mathrm{CD} 8 \mathrm{~T}$ cell change over the 11-month treatment period was observed.

Recently, DNA-dependent protein kinase has been identified as a potential modulator in HIV-1 induced CD4 cell death [19]. Radix Astragali, a major ingredient of Aining Granule, was shown to induce $\mathrm{T}$ lymphocytes cell proliferation and phosphorylation of extracellular signal-regulated kinase [20]. Ginseng is another major ingredient in Aining Granule that was reported for slowing CD4 T cell depletion in HIV-infected patients [21]. Another study showed that ginseng can promote CD4 $\mathrm{T}$ cell proliferation and dendritic cell stimulation [22]. Although Chinese medicine is a complex mixture of heterogeneous ingredients, considering social belief, HAART availability and toxicity considerations, the beneficial effects of Chinese medicine should be further explored to improve the quality of life for the PLHIV in China.

\section{Acknowledgement}

This work was supported by Stanley Ho Centre for Emerging Infectious Diseases and Core Laboratory facilities, Li Ka Shing Institute of Health Sciences, The Chinese University of Hong Kong. We thank Liu Ying for her coordination.

\section{References}

1. Xing $H$, Wang $X$, Liao L, Ma $Y$, Su B, et al. (2013) Incidence and associated factors of HIV drug resistance in Chinese HIV-infected patients receiving antiretroviral treatment. PLoS One 8: e62408.

2. Li H, Wang Z, Cui W, Liang Y, Xin T, et al. (2005) [Study on adherence and interrelated factors of acquired immunedeficiency syndrome patients receiving antiretroviral treatment]. Zhonghua Liu Xing Bing Xue Za Zhi 26: 507-510.

3. Pan-Hammarström Q1, Wen S, Hammarström L (2006) Cytokine gene expression profiles in human lymphocytes induced by a formula of traditional Chinese medicine, vigconic VI-28. J Interferon Cytokine Res 26: 628-636.

4. Yan Z, Hua H, Xu Y, Samaranayake LP (2012) Potent Antifungal Activity of Pure Compounds from Traditional Chinese Medicine Extracts against Six Oral Candida Species and the Synergy with Fluconazole against Azole-Resistant Candida albicans. Evid Based Complement Alternat Med: 106583.

5. Huang SZ, Zhang X, Ma QY, Zheng YT, Xu FQ, et al. (2013) Terpenoids and their anti-HIV-1 activities from Excoecaria acerifolia. Fitoterapia 91: 224-230.

6. Liu X, Han Y, Peng K, Liu Y, Li J, et al. (2011) Effect of traditional Chinese medicinal herbs on Candida spp. from patients with HIVIAIDS. Adv Dent Res 23: $56-60$.

7. Wang J, Yang FZ, Zhao M, Zhang YH, Zhang YX, et al. (2006) Randomized double-blinded and controlled clinical trial on treatment of HIVIAIDS by Zhongyan-4. Chin J Integr Med 12: 6-11.

8. Wang J, Li Y, Tang Y-L, Lin H-S, Wu X-F, et al. (2013) Effect of Immune No. 2 on the immune reconstitution in patients with HIVIAIDS after highly active antiretroviral treatment: a randomized double blind placebo controlled clinical trial. Chin J Integr Med 19: 340-346.

9. Wang J, Zou W (2011) Practices, challenges, and opportunities: HIV/AIDS treatment with traditional Chinese medicine in China. Front Med 5: 123-126.

10. Wang J, Liu Y, Zou W, He L, Yan S, et al. (2008) Clinical Observations on 100 HIVIAIDS Cases Treated with Chinese Herb Aining Granule plus HAART. Chinese J AIDS STD 14: 101-107.

11. Leung RK, Dong ZQ, Sa F, Chong CM, Lei SW, et al. (2014) Quick, sensitive and specific detection and evaluation of quantification of minor variants by highthroughput sequencing. Mol Biosyst 10: 206-214.

12. Leung RK, Zhou JW, Guan W, Li SK, Yang ZF, et al. (2013) Modulation of potential respiratory pathogens by $\mathrm{pH} 1 \mathrm{~N} 1$ viral infection. Clin Microbiol Infect 19: $930-935$ 
Citation: Ross LK, Frances LFS, Yu-wen C, Yang X, Jian W (2015) Aining Granule Stabilizes the Decline of CD4 Cell Count in HAART-Receiving HIVI AIDS Patients Having Virologic Failure. J Data Mining Genomics Proteomics 6: 165. doi:10.4172/2153-0602.1000165

13. Leung RKK, Wang Y, Ma RCW, et al. (2013) Using a multi-staged strategy based on machine learning and mathematical modeling to predict genotypephenotype risk patterns in diabetic kidney disease: a prospective case-control cohort analysis. BMC Nephrol 14: 162.

14. Cen Y, Leung RK-K, Zhang F, et al. (2013) The Association between YangDeficient Constitution and Clinical Outcome of Highly Active Antiretroviral Therapy on People Living with HIV. Evid Based Complement Alternat Med 2013: 201857.

15. Fukasawa Y, Leung RKK, Tsui SKW, Horton P (2014) Plus ça change evolutionary sequence divergence predicts protein subcellular localization signals. BMC Genomics 15: 46.

16. Wang X, Yang L, Li H, Zuo L, Liang S, et al. (2011) Factors associated with HIV virologic failure among patients on HAART for one year at three sentinel surveillance sites in China. Curr HIV Res 9: 103-111.

17. Liao L, Xing H, Su B, Wang Z, Ruan Y, et al. (2013) Impact of HIV drug resistance on virologic and immunologic failure and mortality in a cohort of patients on antiretroviral therapy in China. AIDS 27: 1815-1824.
18. Xing H, Ruan Y, Li J, Shang H, Zhong P, et al. (2013) HIV drug resistance and its impact on antiretroviral therapy in Chinese HIV-infected patients. PLoS One 8: e54917.

19. Cooper A, García M, Petrovas C, Yamamoto T, Koup RA, et al. (2013) HIV1 causes CD4 cell death through DNA-dependent protein kinase during viral integration. Nature 498: 376-379.

20. Gao QT, Cheung JK, Li J, Chu GK, Duan R, et al. (2006) A Chinese herba decoction, Danggui Buxue Tang, prepared from Radix Astragali and Radix Angelicae Sinensis stimulates the immune responses. Planta Med 72: $1227-$ 1231.

21. Sung H, Kang SM, Lee MS, Kim TG, Cho YK (2005) Korean red ginseng slows depletion of CD4 T cells in human immunodeficiency virus type 1-infected patients. Clin Diagn Lab Immunol 12: 497-501.

22. Kim MH, Byon YY, Ko EJ, Song JY, Yun YS, et al. (2009) Immunomodulatory activity of ginsan, a polysaccharide of panax ginseng, on dendritic cells. Korean J Physiol Pharmacol 13: 169-173. 